\section{As unidades fraseológicas dos contos Le Petit Nicolas em dicionários bilíngues francês/português*}

The phraseological units of Le Petit Nicolas short stories in bilingual French / Portuguese dictionaries

Angelo de Souza SAMPAIO (UFBA) angelo.sampaio@ufba.br

Silvana Soares Costa RIBEIRO (UFBA) silvanar@ufba.br

Recebido em: 30 de set. de 2020. Aceito em: 20 de out. de 2020.

*O presente trabalho é oriundo da pesquisa de doutorado do autor, sob orientação da coautora. Trata-se de um recorte do material estudado para o exame de qualificação, defendido e aprovado em 11 de dezembro de 2019.
SAMPAIO, Angelo de Souza; RIBEIRO,

Silvana Soares Costa. As unidades

fraseológicas dos contos Le Petit

Nicolas em dicionários bilíngues

francês/português. Entrepalavras,

Fortaleza, v. 11, n. esp., p. 366-389,

ago. 2021. DOI: $10.22168 / 2237-6321-$

10 esp2109.

Resumo: Estudos em Fraseologia (BOLLY, 2011; MONTEIRO-PLANTIN, 2017) apontam que falantes estrangeiros de uma determinada língua demonstram maior dificuldade em compreender o sentido global de unidades fraseológicas (UF), mesmo conhecendo o sentido individual que, habitualmente, é empregado a cada lexia que as compõem. Um bom exemplo disso está na compreensão das UFs presentes nos contos da coletânea de livros infanto-juvenis Le Petit Nicolas, comumente utilizada como leitura paradidática durante as aulas de Francês Língua Estrangeira (FLE). Pesquisas indicam que a maioria dos estudantes de línguas estrangeiras em níveis iniciais fazem uso de dicionários bilíngues para dirimir dúvidas quanto ao vocabulário da língua estrangeira em aprendizagem (ZUCCHI, 2010a). Em trabalhos anteriores (SAMPAIO; RIBEIRO, 2018), observamos que, embora as expressões idiomáticas tenham ganhado alguma atenção dos dicionários bilíngues e/ou fraseológicos no Brasil, os demais tipos de UFs não estão contemplados em tais obras lexicográficas, o que, possivelmente, aumenta a complexidade da leitura. Assim, o presente trabalho buscou identificar e catalogar as UFs presentes 
na série já mencionada, de modo que se pudesse melhor averiguar a dicionarização em obras lexicográficas bilíngues mais frequentemente consultadas por aprendizes de FLE no Brasil. Foram consultados cinco dicionários bilíngues (dois de uso geral e três fraseológicos). Para este artigo, o corpus foi limitado aos contos do primeiro livro da série. Os resultados mostraram que os dicionários bilíngues de francês no Brasil ainda carecem de atenção quanto à presença de UFs.

Palavras-chave: Fraseologia. Lexicografia. Fraseografia. Dicionários bilíngues. Le Petit Nicolas.

Abstract: Phraseology studies (BOLLY, 2011; MONTEIRO-PLANTIN, 2017) point out that foreign speakers of a given language demonstrate greater difficulty in understanding the global meaning of phraseological units (PU), even knowing the individual meaning that is usually used in each lexia that compose them. A good example of this is in the understanding of the PUs present in the short stories in the children's book collection Le Petit Nicolas, commonly used as reading paradidactic during French Foreign Language (FFE) classes. Research indicates that most foreign language students at initial levels make use of bilingual dictionaries to resolve doubts about the vocabulary of the foreign language in learning (ZUCCHI, 2010a). In previous works (SAMPAIO; RIBEIRO, 2018), we observed that, although idioms have gained some attention from bilingual and/or phraseological dictionaries in Brazil, the other types of PUs are not included in such lexicographic works, which possibly increases the complexity of reading. Thus, the present work sought to identify and catalog the PUs present in the aforementioned series, so that one could better ascertain the dictionary in bilingual lexicographic works most frequently consulted by French apprentices in Brazil. Five dictionaries were consulted (two for general use and three for phraseology). For this article, the corpus was limited to the tales from the first book in the series. The results showed that the bilingual French dictionaries in Brazil still lack attention regarding the presence of PUs.

Keywords: Phraseology. Lexicography. Phraseography. Bilingual dictionaries. Le Petit Nicolas.

\section{Introdução}

Este trabalho surgiu das inquietações dos autores, enquanto professor e aprendiz de francês como língua estrangeira (FLE), quanto à forma como certas expressões linguísticas são compreendidas pelos estudantes, especialmente durante as aulas de leitura. Ao longo de nossa experiência profissional e acadêmica, percebemos que os estudantes de FLE demonstravam certa dificuldade, ou mesmo resistência, em compreender o sentido de determinadas estruturas léxicas da língua em questão.

No tocante ao ensino/aprendizado do léxico de uma língua estrangeira, os estudos em Fraseologia (BOLLY, 2011; MONTEIROPLANTIN, 2017) apontam que a aquisição da fraseologia dessa língua configura-se em um grande obstáculo para quem se dispõe a aprendêla. Tagnin (2013, p. 15) ressalta que essas expressões são "difíceis" 
v. 11 (esp.)

$366-389$

ago.

2021

[...] provavelmente porque têm de ser aprendidas individualmente, isto é, uma a uma, pois não há regra que as gere. Entretanto, não são apenas as assim chamadas expressões idiomáticas que têm de ser aprendidas desse modo. Há toda uma gama de unidades linguísticas convencionais que o aprendiz de uma língua estrangeira desconheceria, mesmo que conhecesse toda a gramática e soubesse todo o dicionário básico de cor.

As unidades fraseológicas (UF) são definidas com base em propriedades muito particulares: são polilexicais; apresentam certo grau de fixidez semântica, sintática e pragmática; apresentam alta frequência de uso e certo grau de idiomaticidade (ou opacidade semântica), isto é, são semanticamente não composicionais.

Por conta do caráter opaco, o significado de determinadas UF não pode ser entendido pela definição de cada lexia que a compõe, mas, ao contrário, pela sua totalidade. Exemplificando: a) João comprou um 'pão duro' para fazer torradas; b) João é muito 'pão duro', compra sempre o mais barato.

A sentença (a) pode ser facilmente compreendida por um falante do português brasileiro, seja nativo ou estrangeiro, visto que o sentido da expressão 'pão duro', em destaque, é composicional, isto é, o entendimento da expressão é resultante da somatória do significado das palavras 'pão' + 'duro'. Por outro lado, o mesmo não acontece em (b). Nesse caso, o sentido da expressão 'pão duro' não é composicional e deve ser compreendido em sua globalidade: 'pão duro' = sovina. Em outras palavras, o enunciado em (a) é semanticamente transparente, ao passo que em (b) é semanticamente opaco.

Embora date do início dos anos 1960, a coletânea francesa de contos infanto-juvenis Le Petit Nicolas (GOSCINNY; SEMPÉ, 19601964) é tradicionalmente utilizada como material autêntico nas aulas de francês e recomendada como leitura paradidática (CAPELLE; MENAND, 2009), seja como língua materna, seja como língua estrangeira (CHATENET, 2020). Consideramos como material autêntico aqueles que não são concebidos originalmente para fins didáticos, mas sim para atender a uma demanda sociocultural da comunidade nativa da língua (DELUIGI; ROGGO, 2016, p. 11). São assim chamados porque permitem ao professor contextualizar a aprendizagem da língua estrangeira em uma situação autêntica, viva e natural de uso da língua (MEYSSONNIER, 2005, p. 6). 
No que tange à dicionarização de tais UFs, trabalhos anteriores (SAMPAIO; RIBEIRO, 2018) revelaram que, ainda que as expressões idiomáticas tenham atraído a atenção de alguns dicionários gerais e fraseológicos ${ }^{1}$ bilíngues, outras UFs foram deixadas de lado. Nessa esteira, o presente trabalho, que teve como ponto de partida a pesquisa de doutorado em andamento do autor, sob orientação da coautora, buscou apresentar os primeiros resultados da pesquisa.

Nessa etapa da investigação, buscamos identificar e catalogar as UFs presentes no primeiro livro da coletânea (GOSCINNY; SEMPÉ, 1960) e averiguar o nível de frequência, das UFs catalogadas na obra, em dicionários bilíngues, gerais e fraseológicos, mais difundidos no Brasil. Neste trabalho, apresentamos os resultados obtidos sobre colocações, pragmatemas, expressões idiomáticas e possíveis UFs compostas por sintagmas nominais.

\section{Referencial teórico}

O signo linguístico, tal como postulado por Ferdinand de Saussure (2006 [1916]), manifesta-se a partir de duas dicotomias básicas. De um lado, encontra-se a oposição signo lexical vs. signo gramatical e, de outro, a oposição signo elementar vs. signo complexo. Os signos complexos podem ser expressados a partir de, ao menos, duas formas: quer seja pela junção de um signo lexical e um signo gramatical, quer seja pela união de vários signos lexicais em um único signo linguístico, quer dizer, que seja capaz de remeter, integralmente, a um único significado. Partido do postulado saussuriano, Pottier (1974, p. 266-268) amplia o conceito de signo complexo e faz as seguintes distinções: a) lexia simples; b) lexia composta; c) lexia complexa e d) lexia textual.

A lexia simples corresponde ao signo (ou palavra) em seu sentido tradicional, a exemplo de 'cadeira', 'por' ou 'canta'. A lexia composta resulta de uma integração semântica de várias lexias simples que se manifestam formalmente e que podem ser separadas por hifens, como em 'pé-de-moleque' e 'beija-flor', ou por justaposição, tais como 'pontapé' e 'girassol'. Acreditamos que esse também seja o caso das

${ }^{1}$ Ainda que grande parte dos dicionários fraseológicos difundidos no Brasil não recebam oficialmente essa nomenclatura, os consideramos como tal, seguindo a definição de dicionário fraseológico trazida por Marques e Budny (2020). Para as autoras, esse termo é um hiperônimo que abarca todas as publicações lexicográficas que tratam da dicionarização de UFs, independentemente de sua tipologia. 
v. 11 (esp.)

366-389

ago.

2021

lexias formadas por aglutinação, a exemplo de 'aguardente' e 'planalto'. A lexia complexa é a lexicalização de uma dada sequência de lexias simples, como 'água potável' e 'cachorro quente'. Segundo Pottier (1974), as siglas também são consideradas como lexias complexas. Esse é o caso de 'IBGE', 'FGTS', 'ONG', entre outras. A lexia textual, por sua vez, corresponde aos casos em que a lexia complexa ganha a dimensão de um enunciado ou de um texto, tais como hinos nacionais, orações, provérbios e outros.

Tomando por base questões relativas aos signos linguísticos compostos, complexos e textuais, observamos que a Fraseologia é o campo teórico que se dedica à abordagem desses signos linguísticos. É, portanto, a área de investigação dos estudos lexicais que tem como objeto de análise as combinações fixas de unidades léxicas de uma determinada língua. As UFs possuem certo grau de idiomaticidade e alta frequência de uso. As lexias que as compõem estão interligadas semântica, pragmática e sintaticamente de tal modo que seu significado é dado, majoritariamente, pela totalidade de seus elementos (ORTIZ ALVAREZ; UNTERNBÄUMEN, 2011, p. 9).

No que se refere à delimitação e classificação das UFs, a literatura atual (GONZÁLEZ-REY, 2015; MEJRI, 2003, 2011, 2017; MEJRI; BLANCO, 2018; MOGORRÓN, 2012; MONTEIRO-PLANTIN, 2014; PAMIES, 2018; SFAR, 2007, 2010, 2013; TAGNIN, 2013, para citar os autores mais conhecidos com publicações em língua portuguesa e francesa) define a seguinte tipologia para as UFs: colocação, expressão idiomática, pragmatema; locução; construção com verbo suporte, perífrase verbal, parêmia, entre outros menos frequentes.

Neste artigo, trataremos apenas dos casos de colocações, expressões idiomáticas, parêmias e pragmatemas. As colocações são UFs constituídas através da coocorrência léxico-sintática de certas lexias que são usualmente empregadas de forma conjunta. Polguère (2018, p. 65, grifos do autor) define as colocações do seguinte modo:

Uma colocação é um sintagma $A B$ (ou $B A$ ) tal que, para construilo, o Locutor seleciona $A$ livremente de acordo com o sentido ' $A$ ', ao passo que ele seleciona ' $B$ ' para exprimir junto de $A$ um sentido ' $\mathrm{s}$ ' em função de restrições impostas por $A$.

A exemplos de colocações em português, podemos citar 'prato principal', 'pão francês', 'chave de fenda'. As colocações são consideradas como unidades semifraseológicas, ao contrário das expressões idiomáticas. A característica primordial das expressões 
idiomáticas está, portanto, na opacidade semântica. Dito de outro modo, o sentido das expressões idiomáticas não é composicional, ao passo que o das colocações é. Xatara (1998, p. 149) define expressão idiomática como "uma lexia complexa indecomponível, conotativa e cristalizada em um idioma pela tradição cultural". Exemplos: "bater as botas' (morrer) e 'cair a ficha' (entender).

O termo parêmia, por sua vez, serve como um conceito guarda-chuva que abarca as expressões comumente conhecidas como provérbios, ditos populares, máximas etc. (GONZÁLEZ-REY, 2015, p. 65), que são passadas de geração a geração, tradicionalmente pela oralidade, e que representam a cultura de um povo. As parêmias são caracterizadas por apresentarem didaticidade, atemporalidade e imparcialidade (MONTEIRO-PLANTIN, 2014, p. 67-70). Exemplo: 'quem tem boca vai a Roma'.

Por fim, os pragmatemas remetem às marcas de discurso, aos atos de fala que caracterizam não apenas a polidez ou impolidez presentes na comunicação, mas também às fórmulas pré-fabricadas que conectam logicamente as informações transmitidas quer seja na oralidade, quer seja pela escrita. Em outras palavras, os pragmatemas representam o nível mais pragmático possível da Fraseologia, isto é, "o nível de uso da língua em interações sociais" (TAGNIN, 2013, p. 109). Exemplos: 'Feliz natal', 'sendo assim', 'em vista disso'.

\section{Percurso metodológico}

Como mencionado, o corpus de nossa pesquisa é composto por dados fraseológicos presentes na coletânea francesa de contos infantojuvenis Le Petit Nicolas (GOSCINNY; SEMPÉ, 1960-1964). As histórias presentes nos primeiros livros foram publicadas inicialmente no jornal Sud-Ouest Dimanche, em forma de folhetins, com periodicidade semanal, e, posteriormente, agrupadas em formato de livros. A Figura 1 exibe a cópia das capas dos cinco principais livros, publicados pela editora Denoël na coleção Folio Junior, com ambos os autores em vida. 
v. 11 (esp.) 366-389 ago. 2021

Figura 1 - Capas dos cinco primeiros livros Le Petit Nicolas (GOSCINNY; SEMPÉ, 1960-1964)

\begin{tabular}{|c|c|c|c|c|}
\hline $\begin{array}{l}\text { Sempé-Goscinny } \\
\text { Le petit Nicolas }\end{array}$ & $\begin{array}{l}\text { Sempé-Goscinny } \\
\text { Les récrés } \\
\text { du petit Nicolas }\end{array}$ & $\begin{array}{l}\text { Sempé-Goscinny } \\
\text { Les vacances } \\
\text { du petit Nicolas }\end{array}$ & $\begin{array}{l}\text { Sempé-Goscinny } \\
\text { Le Petit Nicolas } \\
\text { et les copains }\end{array}$ & $\begin{array}{l}\text { Sempé-Goscinny } \\
\text { Le petit Nicolas } \\
\text { a des ennuis }\end{array}$ \\
\hline
\end{tabular}

Fonte: Coleção dos autores - foto montagem - arquivo dos pesquisadores.

Para compor o corpus deste artigo, foram consideradas as UFs observadas no primeiro volume da coletânea, isto é, o livro que dá nome à série: Le Petit Nicolas (GOSCINNY; SEMPÉ, 1960). Embora atualmente os direitos legais dessa obra pertençam à editora IMAV éditions (CHATENET, 2020), utilizamos para a coleta dos dados a versão original, com textos integrais, pertencente à coleção Folio, da editora Denoël. A obra, em brochura, possui $11 \mathrm{~cm}$ de largura por $18 \mathrm{~cm}$ de altura e totaliza 160 páginas.

De modo geral, os contos, sempre narrados em primeira pessoa por Nicolas, criança de aproximadamente oito anos, apresentam as mesmas configurações quanto a sua formatação: são compostos por cerca de oito a nove páginas; exibem desenhos, sempre assinados por Sempé, que ilustram as ações dos personagens; os desenhos apresentam-se em dimensões diversas e seu posicionamento na página varia de conto a conto, por vezes, estendendo-se por uma ou duas páginas, cobrindo, sozinhos, a sua totalidade, por vezes ocupando apenas metade da página, competindo com os textos escritos; normalmente, em número de quatro por conto, os desenhos são sempre em preto e branco. Tais padrões certificam que as histórias eram previstas, tanto em termos de texto escrito quanto em texto imagético, para serem editados em um suporte de jornal, o qual, como sabemos, tem um número predeterminado e limitado de caracteres e, dificilmente, sobretudo na década de 1960, dispunha de recursos de impressão colorida.

Considerando que nossa pesquisa está baseada em textos autênticos específicos, que, no início da pesquisa, não foram cogitados os recursos disponíveis pela Linguística de Corpus para a realização da coleta de dados e que o levantamento já havia sido iniciado quando tomamos conhecimento dessas possibilidades, optamos por fazer um 
levantamento de dados em estilo tradicional, isto é, através da efetiva leitura dos contos e da identificação e catalogação manual dos dados fraseológicos ali presentes. Tal decisão foi bastante oportuna, visto que a leitura trouxe vantagens para o desenvolvimento da pesquisa, em especial a possibilidade de termos uma percepção completa do estilo de narrativa do autor e de verificar a possibilidade de haver expressões idiossincráticas presentes no texto.

Durante o processo de leitura dos contos estabelecemos os seguintes critérios de tabulação das UFs coletadas: a) categoria gramatical (se sintagma nominal ou verbal); b) tipo de UFs. Até este ponto da pesquisa, buscamos enquadrar as UFs em basicamente cinco categorias: colocações, EI, parêmias, pragmatemas e 'outros'. Reservamos o rótulo 'outros' para casos em que tivéssemos dificuldades de determinar o tipo de UF; c) localização da UF no conto; d) tradução literal e e) tradução equivalente.

Tendo a tabulação dos dados sido concluída, estabelecemos, como nova etapa de testagem da metodologia, a averiguação de como se dá a dicionarização das UFs coletadas em obras lexicográficas de referência. Nosso intuito era, em primeira instância, validar as expressões duvidosas, ou seja, aquelas que conotassem características de uma UF, mas que não nos transmitissem segurança de classificação e, em segunda instância, verificar a dimensão do acesso à definição das UFs que um leitor brasileiro poderia ter de maneira autônoma. Para tanto, elegemos dois dicionários bilíngues, francês/português, a saber: Dicionário Larousse francês-português (GALVEZ, 2006), doravante Larousse, e Minidicionário francês Michaelis (AVOLIO; FAURY, 2010), doravante Michaelis.

Tais dicionários foram escolhidos por serem, segundo a nossa experiência e pesquisas empíricas atuais (ZUCCHI, 2010a), os de acesso mais facilitado por parte dos estudantes brasileiros de francês. Quer seja por questões financeiras, uma vez que são os mais baratos do mercado, quer seja pela falta de consciência fraseológica e, consequentemente, pela ausência de consultas a dicionários fraseológicos. Embora a história dos métodos de ensino de línguas estrangeiras (CUQ; GRUCA, 2017) demonstre que muitos professores não encorajam o uso de dicionários durante o processo de aquisição da língua, "vemos que o dicionário bilíngue pequeno é uma das primeiras aquisições dos estudantes, apesar de não ser utilizado em sala de aula com método e sistematicamente" (ZUCCHI, 2010b, p. 1153). 
v. 11 (esp.) 366-389 ago. 2021

Portanto, conscientes de que as obras lexicográficas escolhidas são dicionários gerais, isto é, voltados para o uso geral da língua, e não para fins especializados e/ou fraseológicos, a consulta a eles foi feita em duas etapas: a) busca pela UF em sua totalidade e b) busca separada de cada uma das lexias que compõem a UF.

A primeira busca objetivava verificar se os dicionários contemplavam, de algum modo, as UFs. Uma vez verificada a ausência de registro da UF em sua totalidade, buscávamos em separado, através da consulta das lexias que constituem a unidade, se a UF era mencionada por meio de outras acepções ou expressas em abonações.

Completada a consulta nos dicionários gerais, passamos para a fase de verificação em dicionários fraseológicos. Primeiramente, elegemos duas obras, a saber: Dicionário de idiomatismos francêsportuguês, português-francês (MATTOS; BRETAUD, 1990), doravante Dicionário de idiomatismos, e Dicionário de Expressões Idiomáticas (XATARA, 2013), doravante Dicionários de expressões. Sendo o primeiro um livro físico (analógico) e o segundo uma obra lexicográfica bilíngue em formato virtual (digital), disponível em plataforma on-line e de acesso gratuito, acreditávamos estar contemplados.

Entretanto, considerando a data de publicação do Dicionário de idiomatismos, decidimos por selecionar uma terceira referência, mais recente, igualmente em formato analógico. Optamos pelo volume de língua francesa da série Xeretando a linguagem (ZAVAGLIA; SILVA; XATARA, 2010), disponível para venda nas principais livrarias do país, com baixo custo de investimento e escrito em língua portuguesa. A obra propõe-se a apresentar definições de EI, provérbios ou ditos populares empregados no dia a dia, falsos cognatos, expressões construídas a partir de nomes de cores, gírias e exemplos de insultos e xingamentos, o que as autoras denominam de linguagem vulgar ou obscena.

\section{Análise dos dados}

O livro 1, composto por dezenove contos, apresentou um total de 1258 ocorrências de 431 UFs distintas. No que se refere ao primeiro item classificatório a ser observado, qual seja, a categoria gramatical, notamos que das 431 ocorrências totais de UFs encontradas ao longo da leitura do livro em análise, 52\% (isto é, 222 UFs distintas) são elaboradas a partir de sintagmas nominais, ao passo que 48\% (o que correspondea um total de 209 UF diferentes) são constituídas por sintagmas verbais, tal como exposto no Gráfico 1: 
Gráfico 1 - Classificação da categoria gramatical das UFs encontradas no volume 1 da coletânea Le Petit Nicolas (GOSCINNY; SEMPÉ, 1960)

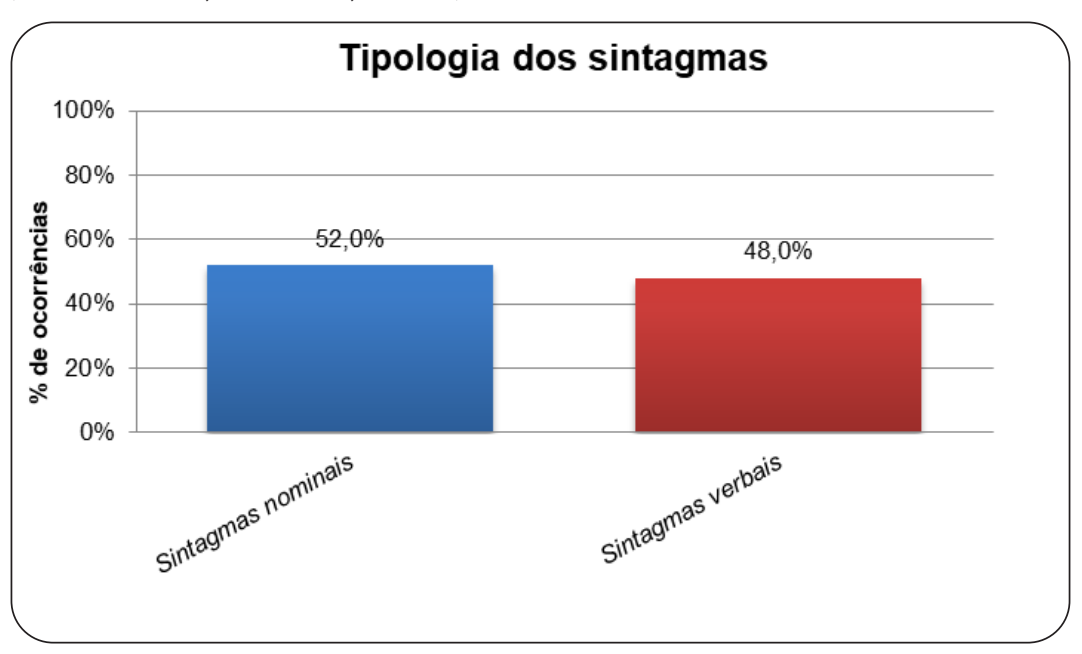

Fonte: os autores.

Como apresentado pelo Gráfico 1, os sintagmas nominais estão em maior número. Contudo, acreditamos haver um equilíbrio entre as categorias, visto que a diferença quantitativa entre uma e outra é de apenas quatro pontos percentuais.

De modo a melhor otimizar o tempo das análises que aqui pretendemos expor, aplicaremos um recorte aos sintagmas nominais. Desse modo, nas subseções que seguem, constam os resultados alcançados pela tabulação dos sintagmas nominais e pela pesquisa em dicionários, gerais e fraseológicos.

Análise linguística: a tipologia dos sintagmas nominais

Os dados fraseológicos compostos por sintagmas nominais foram submetidos à classificação de acordo com a sua tipologia. Das 222 UFs construídas a partir de sintagmas nominais, observamos que $72 \%$ (158 formas diferentes que se repetem em um total de 425 vezes) são de colocações. Essa é, portanto, a categoria com maior frequência, tal como informado por meio do Gráfico 2, a seguir. 
v. 11 (esp.) $366-389$ ago. 2021

Gráfico 2 - Tipologia das UFs em análise

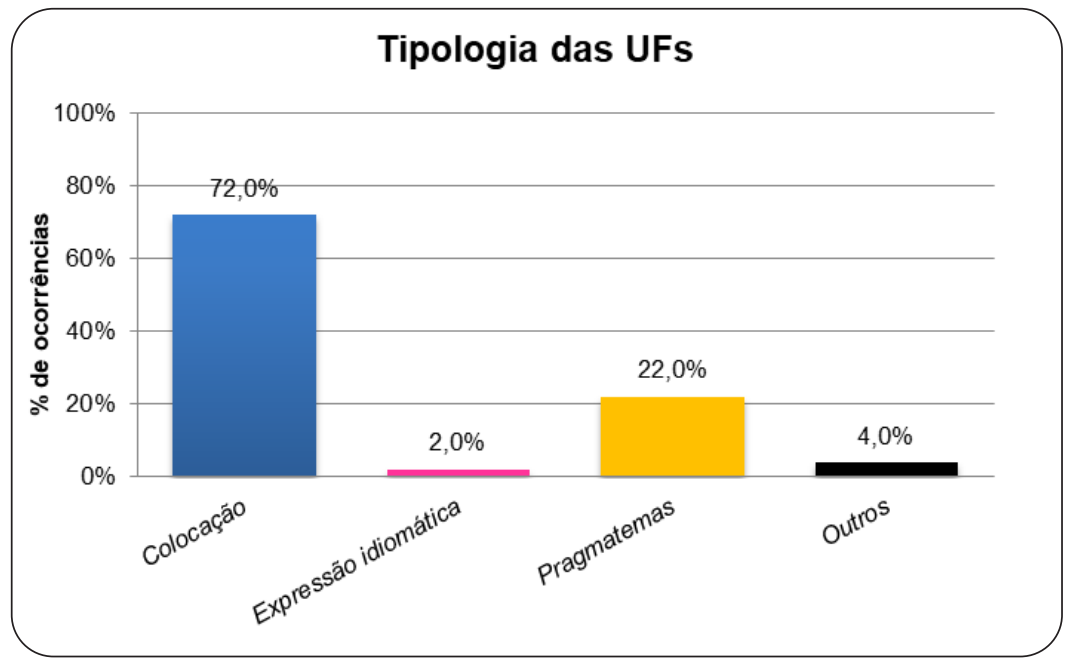

Fonte: os autores.

Em segundo lugar, encontram-se os pragmatemas, com 22\% dos dados (49 UFs distintos e 197 repetições). Em terceira posição estão as UFs classificadas como 'outros'. Tal rótulo perfaz um total de 4\% dos dados (10 entidades léxicas diferentes, com 50 repetições). Foram etiquetadas nessa categoria unidades lexicais que nos pareciam fraseológicas, mas que não conseguimos classificar de imediato. Em última posição, encontram-se as EIs, com $2 \%$ dos dados ( 5 expressões que ocorrem em uma frequência de 7 vezes ao todo). Quanto às parêmias, não foi documentada nenhuma realização.

Análise lexicográfica: o que revelam os dicionários

Uma vez tendo sido feita a pesquisa lexicográfica dos dados fraseológicos formados por sintagmas nominais do livro 1 da série Le Petit Nicolas nos dicionários selecionados para a consulta, a saber: a) Larousse; b) Michaelis; c) Dicionário de Idiomatismos; d) Dicionário de Expressões e e) Xeretando a linguagem, passamos à descrição dos dados por obra lexicográfica.

Primeiramente, traremos os resultados obtidos pela pesquisa lexicográfica em dicionários gerais. Em seguida, apresentaremos os resultados da consulta em dicionários fraseológicos. 


\section{Larousse}

A pesquisa lexicográfica realizada no Larousse resultou no que vem exposto no Gráfico 3.

Gráfico 3 - Resultados da verificação da dicionarização no Larousse

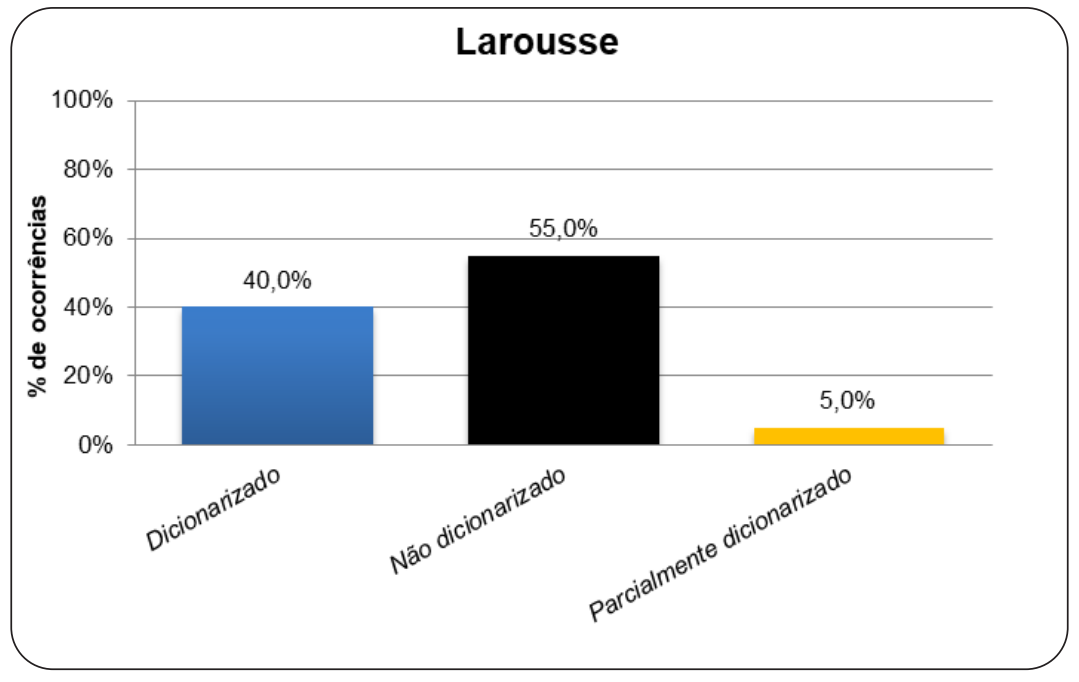

Fonte: os autores.

Como se vê, destacado em azul, foi contabilizado um total de 40\% de UFs dicionarizadas no Larousse. Entretanto, observamos que mais da metade dos dados, isto é, 55\%, realçado em preto, não foi dicionarizada. Ademais, o Larousse apresenta $5 \%$ de dicionarizações parciais.

Esclarecemos que, para efeito de averiguação do possível registro das UFs que compõem o nosso corpus nos dicionários, sejam eles gerais ou fraseológicos, foi feita uma dupla consulta. Ou seja, foram observadas ambas as lexias que compõem a UF. Consideramos como sendo dicionarizado não apenas os casos em que a própria UF assumia a posição de verbete, mas também quando ele era indicado por intermédio de acepções. Os casos em que a UF era apresentada mediante a utilização de abonos, isto é, como exemplos, dentro de uma estrutura maior, mas sem explicitação de sua definição, ou ainda quando apenas a base da colocação estava registrada, deixando em aberto as possibilidades de seleção do colocado, consideramos como a UF sendo parcialmente dicionarizada.

O item (1) exibe exemplos de UFs parcialmente dicionarizadas pelo Larousse. 
v. 11 (esp.) 366-389 ago. 2021

\section{(1) a Tout d'un coup \\ b Appareil \\ c Espèce de guignol}

A UF tout d'un coup ('de repente', em tradução livre), em (1a), está dicionarizada pelo Larousse como tout à coup. Ambos os registros existem em língua francesa e são considerados como sinônimos. Contudo, aquela que é empregada por Goscinny e Sempé (1960) na fala de Nicolas não é dicionarizada. Considerando a época em que as histórias do Petit Nicolas foram escritas, não sabemos se a forma tout d'un coup é uma variante que estava em maior uso nesse período.

A UF appareil, que é um caso de truncamento da UF appareil photo, em (1b), com o sentido de 'máquina fotográfica', é dicionarizada com sua forma polilexical. Entretanto, não há nenhuma menção à possibilidade do emprego da lexia simples appareil, com o mesmo sentido de 'máquina fotográfica', tal como é feito por Nicolas.

Quanto à UF espèce de guignol, em (1c), a informação é dada através de abono, mas sem explicação de que a lexia espèce possa ser empregada como intensificador de insultos, tal como empregada por Nicolas. Porém, outro xingamento é dado como exemplo. Quanto à lexia guignol, é feita apenas a tradução direta para o seu equivalente em língua portuguesa, isto é, 'marionete'. Entretanto, a possibilidade de emprego dessa lexia como xingamento não é mencionada.

Quanto aos tipos de UFs presentes no Larousse, vejamos a seguir.

Gráfico 4 - Classificação dos tipos de UFs no Larousse.



Fonte: os autores. 
A partir do Gráfico 4, observamos que há, no Larousse, maior predominância no registro de colocações, totalizando 64\% das UFs dicionarizadas. Em segundo plano estão os pragmatemas, com 33\% dos resultados obtidos. Além das colocações e dos pragmatemas, verificamos a dicionarização de uma mínima quantidade de UFs sem classificação, isto é, aquelas que não conseguimos catalogar de imediato, com 3\%. As unidades lexicais sem classificação registradas pelo Larousse são comme tout e gros mot. Há ainda a forma aglutinada bonhomme, que também foi dicionarizada com o mesmo sentido empregado por Goscinny e Sempé (1960).

Michaelis

Os resultados acerca da possível dicionarização de UFs depreendidas da série Le Petit Nicolas realizada pelo Michaelis encontram-se expostos no Gráfico 5, a seguir. Nota-se que, em comparação com aquilo que foi observado no Larousse (Gráfico 3), houve uma redução significativa dos dados dicionarizados pelo Michaelis das UFs consideradas na consulta. O Michaelis registrou apenas 19\% das UFs pesquisadas, ao passo que o Larousse dicionarizou $40 \%$ dos dados totais, configurando-se em Michaelis uma redução de mais da metade das UFs observadas.

Gráfico 5 - Resultados da verificação da dicionarização no Michaelis.

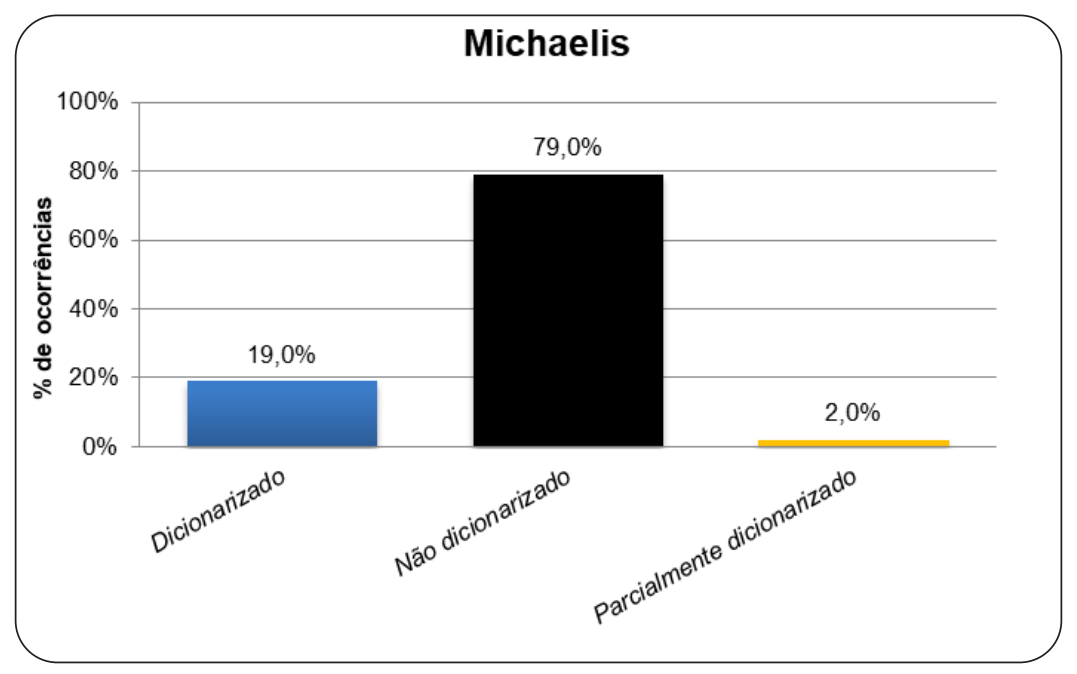

Fonte: os autores.

No tocante às UFs parcialmente dicionarizadas, observamos que essa categoria também foi afetada. Enquanto o Larousse forneceu 
v. 11 (esp.)

366-389 ago. 2021

$5 \%$ de registros parciais, detectamos no Michaelis somente 2\%. Em consequência disso, fica patente a mínima observância de dados fraseológicos pelo Michaelis, uma vez que $79 \%$ dos dados consultados não estão dicionarizados.

No que concerne às UFs parcialmente dicionarizadas pelo Michaelis, no item (2), a seguir, estão alguns exemplos.

$\begin{array}{ll}\text { (2) a } & \text { Tout d'un coup } \\ \text { b } & \text { Montre-bracelet } \\ \text { c } & \text { Petit vaurien } \\ \text { d } & \text { Vilain cafard } \\ \text { e } & \text { Version originale }\end{array}$

Assim como aconteceu no Larousse, constatamos que a UF tout d'un coup, em (2a), está dicionarizada no Michaelis por sua variante tout à coup. Tal informação fortaleceu a nossa hipótese de que a UF tout d'un coup, elegida por Goscinny e Sempé (1960) para marcar a fala de Nicolas seja uma variante pertencente a uma sincronia mais antiga.

Quanto à UF Montre-bracelet, 'relógio-bracelete' ao pé da letra e 'relógio de pulso' em tradução livre, em (2b), está dicionarizada pelo Michaelis, contudo, a ordem das lexias foi invertida. Assim, a forma encontrada no dicionário é bracelet-montre.

Em (2c), a UF petit vaurien é constituída pelo adjetivo petit ('pequeno'), que, aqui, assume o papel de intensificador, frequentemente empregado com insultos, e da lexia vaurien, formada pela aglutinação das lexias valoir ('valer') e rien ('nada'). Um vaurien é, portanto, um xingamento atribuído para injuriar pessoas desprovidas de quaisquer valores morais ou financeiros. Em tradução livre, poderíamos comparar tal insulto às UFs 'João ninguém' ou 'pé rapado', em português. O Michaelis dicionariza o insulto, mas não faz nenhuma menção ao intensificador petit. O mesmo acontece com a injúria vilain cafard, em (2d). O vocábulo cafard é dicionarizado apresentando as suas duas acepções possíveis: 'barata' e 'dedo-duro'. Porém, o autor não explica a possibilidade do uso de intensificadores, quer seja a versão usada por Nicolas e seus amigos, vilain, quer outras possíveis em língua francesa: sale, espèce, petit.

Por fim, em (2e), a colocação version originale ('versão original'), utilizada para denominar filmes, por exemplo, que estejam sendo exibidos tal como desenvolvidos no seu país de origem, isto é, 
sem dublagem, não é registrada pelo Michaelis. Entretanto, o dicionário apresenta as siglas 'VO' e 'VF', por intermédio de abonos, acompanhadas de sua tradução para o português: Versão Original e Versão Francesa. Contudo, não há qualquer menção à UF, deixando para o leitor a responsabilidade da dedução.

Assim como foi feito com o Larousse, averiguamos no Michaelis quais os tipos de UFs foram contemplados entre os 19\% de dicionarizações registradas. Coincidentemente, o Michaelis apresenta exatamente a mesma porcentagem de dicionarização de colocações e pragmatemas que aquela contabilizada pelo Larousse, tal como demonstra o Gráfico 6, a seguir, qual seja: 64\% de colocações, destacada em azul, e $33 \%$ de pragmatemas, em preto.

Gráfico 6 - Classificação dos tipos de UFs dicionarizadas pelo Michaelis.

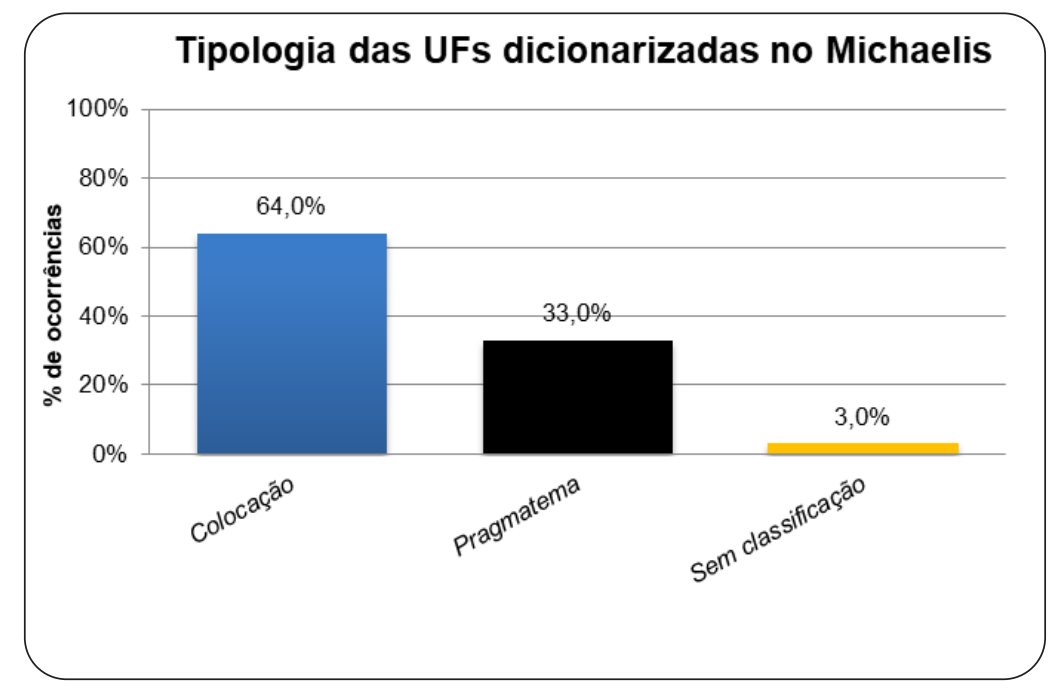

Fonte: os autores.

No entanto, como se vê o gráfico 6, não há nenhum registro de aglutinação, fazendo com que o rótulo 'sem classificação' obtenha, nos cálculos do Michaelis, 3\% dos dados totais. Assim como ocorreu no Larousse, as unidades léxicas sem classificação dicionarizadas pelo Michaelis foram as construções comme tout e gros mot, patenteando a existência de convencionalidade sintática de tais formações.

\section{Dicionário de Expressões}

Como mencionado anteriormente, o Dicionário de Expressões é uma obra lexicográfica em formato digital disponível em plataforma 
v. 11 (esp.) $366-389$ ago. 2021 on-line e de acesso gratuito. Trata-se de um dicionário bilíngue que se propõe a compilar verbetes formados por expressões idiomáticas do português e do francês, apresentando "definição, informações complementares, exemplos, indicação de sinonímia, e seus equivalentes em português europeu (PP), francês hexagonal (FF), francês belga (FB) e canadense (FC)" (XATARA, 2013). Porém, constatamos que nenhuma das UFs compostas por sintagmas nominais presente em nosso corpus foi dicionarizada.

\section{Xeretando a Linguagem}

No que tange a verificação da dicionarização do corpus deste artigo na obra lexicográfica Xeretando a Linguagem, os resultados alcançados foram igualmente pouco representativos. Como mencionado anteriormente, essa obra se predispõe a oferecer, em língua portuguesa, definições e explicações de como são construídas diversas EIs, provérbios e outros idiomatismos da língua francesa. Estão expostos no Gráfico 7 , a seguir, os referidos resultados.

Gráfico 7 - Resultados da verificação da dicionarização em Xeretando a Linguagem.



Fonte: os autores.

Como é observável a partir do Gráfico 7, apenas uma ínfima quantidade de UFs presentes nos contos Le Petit Nicolas foi dicionarizada pelo Xeretando a Linguagem, a saber, $1 \%$ dos dados totais, sinalizado em azul no gráfico. Verificamos também a ocorrência de 1\% de dados parcialmente dicionarizados, destacado em amarelo. Representados pela 
cor preta, observamos que houve $98 \%$ de dados não dicionarizados nessa obra lexicográfica. Os resultados positivos, isto é, aqueles que foram catalogados como total ou parcialmente dicionarizados, encontram-se dispostos no item (3).

(3) $\begin{array}{ll}\text { a } & \text { Àmon tour } \\ \text { b } & \text { Àson tour } \\ \text { c } & \text { Courte paille } \\ \text { d } & \text { Sous-titres }\end{array}$

As UFs em (3a) e (3b) são pragmatemas e correspondem ao rótulo 'parcialmente dicionarizado'. As autoras dão exemplos de utilização do pragmatema, por intermédio de abonos, porém dentro de uma estrutura maior. Não há, contudo, nenhuma explicação quanto a definição ou forma de emprego. Tais pragmatemas são utilizados para sinalizar o turno de fala de alguém: à mon tour ('por minha vez'), à son tour ('por sua vez', $3^{\text {a }}$ pessoa). A UF em (3c) é uma colocação e também está parcialmente dicionarizada, sendo citada dentro de uma estrutura maior: tirer à la courte paille. Em tradução literal, essa colocação corresponde a 'curta palha' e corresponde ao jogo de tirar a sorte com 'palitinho'. Já a UF em (3d), por outro lado, é a única que está totalmente dicionarizada. Sous-titres, 'sob títulos', se traduzido ao pé da letra, equivale em português a 'legenda'.

\section{Dicionário de idiomatismos}

Por último, verificamos a possível dicionarização dos dados do nosso corpus no Dicionário de idiomatismos. Sendo um dicionário bilíngue produzido no Brasil, com características semelhantes às demais obras especializadas que serviram como referência para este trabalho, esperávamos que, assim como ocorreu anteriormente, não obteríamos muitos resultados representativos, especialmente se considerarmos a data de publicação dessa obra lexicográfica, já com quase trinta anos de editoração. Entretanto, nossa hipótese inicial não se confirmou, tal como veremos no Gráfico 8. 
v. 11 (esp.) $366-389$ ago. 2021

Gráfico 8 - Resultados da verificação da dicionarização no Dicionário de idiomatismos.

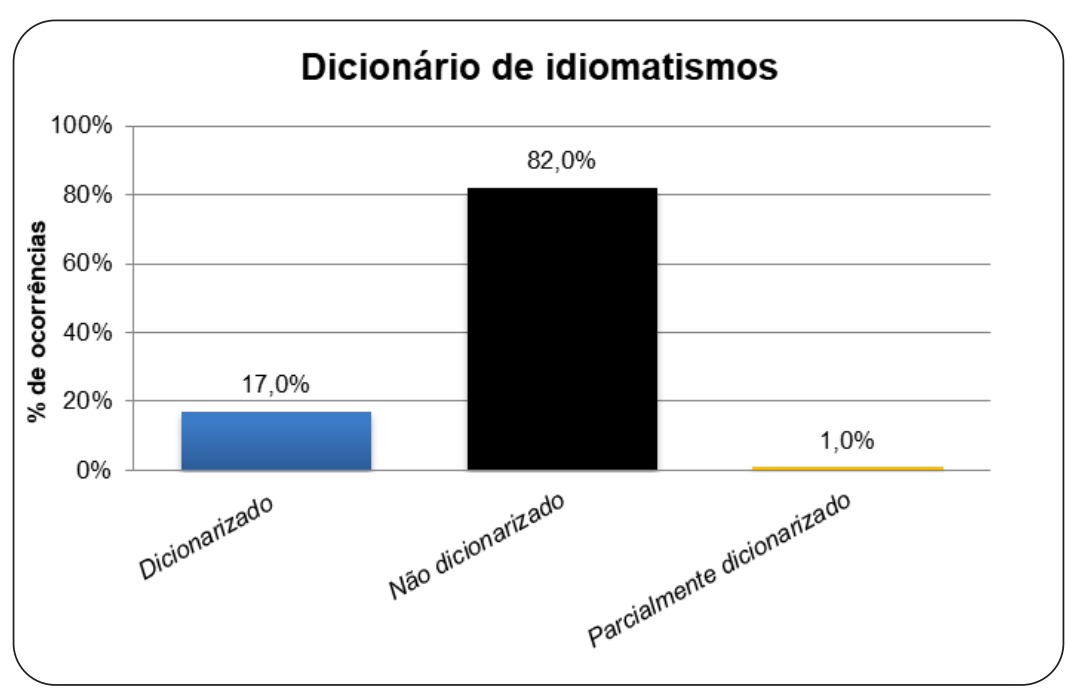

Fonte: os autores.

Ainda que o maior número de registros ocorra na categoria 'não dicionarizado', com $82 \%$ dos dados totais, sinalizado em cor preta no Gráfico 8, houve no Dicionário de idiomatismos um aumento significativo da quantidade de UFs dicionarizadas, quer totalmente, quer parcialmente. Ao todo foram 18\% de UFs registradas, sendo 17\% com dicionarização completa e 1\% com dicionarização parcial, contra 0\% do Dicionário de Expressões e 2\% do Xeretando a Linguagem.

Os casos de dicionarização parcial presentes no Dicionário de idiomatismos estão expostos no item (4).

\section{(4) a Beau temps \\ b Courte paille \\ c L'un l'autre}

A UF beau temps, em (4a), é uma colocação. Ao pé da letra, é traduzida como 'belo tempo', em português. Porém, seu sentido é equivalente a 'bom tempo', no sentido de 'dia ensolarado'. No Dicionário de idiomatismos, tal colocação está registrada com outra definição, em comparação com a empregada por Nicolas, qual seja, 'há muito tempo'.

A UF em (4b), courte paille, dicionarizada parcialmente pelo Xeretando a Linguagem, também é apresentado pelo Dicionário de Idiomatismos com o mesmo sentido que aquele empregado por Nicolas. Porém, dentro de uma estrutura maior: tirer à la courte paille. O registro parcial dessa colocação por dois dicionários fraseológicos nos leva a 
refletir sobre a necessidade de revê-la em seu contexto de uso dentro do conto e de repensar a sua classificação, visto que ambos os dicionários apresentaram a mesma forma dicionarizada.

Por fim, o pragmatema l'un l'autre, em (4c), traduzido literalmente como 'o um e o outro', tem o sentido de 'um e outro' ou 'ambos', em português. O Dicionário de idiomatismos, porém, apresenta tal UF, por meio de abono, em sua forma negativa: ni l'un ni l'autre (nem um, nem outro).

No que concerne às UFs totalmente dicionarizadas nessa obra, destacamos alguns casos mais relevantes: a) a UF tout d'un coup, parcialmente registrada pelos dicionários gerais Larousse e Michaelis, foi completamente dicionarizada, em companhia de sua variante tout à coup, o que valida a sua existência autônoma. Porém, considerando a data de publicação do Dicionário de Idiomatismos, isto é, 1990, nos questionamos se, de fato, a variante tout d'un coup não estaria em uma sincronia mais antiga. Uma investigação futura, possivelmente em consulta a falantes nativos da língua, deverá ser realizada; b) os marcadores conversacionais à tout hasard, après tout, et puis e et puis après, classificados por nós como 'demais casos', vista a nossa incerteza se tais entidades léxicas pudessem realmente ser consideradas como UFs, foram totalmente dicionarizadas. Isso legitima a nossa percepção prévia sobre as características fraseológicas de tais unidades.

Para concluir as análises dos dicionários fraseológicos, verificamos como se deu a presença dos tipos de UFs dicionarizados pelo Dicionário de idiomatismos. O Gráfico 9 apresenta dos resultados.

Gráfico 9 - Classificação dos tipos de UFs dicionarizados pelo no Dicionário de idiomatismos.

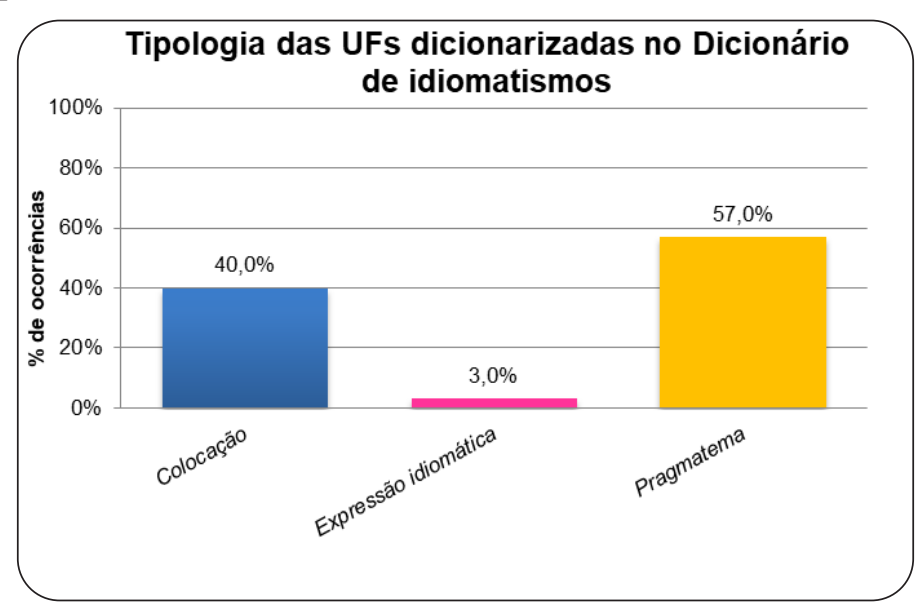

Fonte: os autores. 
v. 11 (esp.) 366-389 ago. 2021

Como se vê no Gráfico 9, há maior número de dicionarizações de UFs do tipo pragmatema no Dicionário de idiomatismos, com 57\% dos dados. Em segunda posição, encontram-se as colocações, com 40\%. Por último, com 3\%, verificamos a dicionarização da única expressão idiomática etiquetada como sintagma nominal, qual seja, à droite et à gauche ('à direita e à esquerda', em tradução literal. 'A torto e a direito', em equivalência fraseológica).

\section{Considerações finais}

Neste trabalho, apresentamos os primeiros resultados obtidos a partir da análise lexicográfica do material fraseológico composto por sintagmas nominais presente nos contos do primeiro livro da série infanto-juvenil Le Petit Nicolas, escrita em 1960 por Goscinny e ilustrada por Sempé.

Considerando que, para este estudo, foram analisadas apenas as construções fraseológicas que se apresentassem em estruturas formadas por sintagmas nominais, somos conscientes de que as UFs do tipo expressão idiomática ou parêmia não se fariam presentes em grande quantidade. Nosso recorte, como vimos, foi constituído, majoritariamente, por colocações e pragmatemas. Uma vez que grande parte das obras lexicográficas bilíngues especializadas em fraseologia de língua francesa, disponível atualmente no mercado brasileiro, é voltada para a compilação de expressões idiomáticas ou parêmias, era esperado que nosso corpus não fosse, por elas, registrado.

Entretanto, é preciso ressaltar que a fraseologia de uma língua não é composta apenas por expressões idiomáticas e parêmias. Como visto, o processo de aprendizado das colocações e dos pragmatemas de uma língua estrangeira parece ser tão complexo e demorado quanto o de qualquer outra UF, em especial aquelas que são semanticamente opacas (TAGNIN, 2013). Por essa razão, consideramos que os dicionários, gerais ou fraseológicos aqui em análise, não dão conta de todo o material fraseológico apresentado por Goscinny e Sempé em seus textos.

Dessa forma, consultar as UFs nessas obras lexicográficas foi uma tentativa de traçar os mesmos passos que um leitor brasileiro teria de percorrer em busca de respostas e, assim, entender na prática como o leitor vive a incerteza da compreensão. Portanto, tendo em vista a carência de fontes lexicográficas de referência capazes de dar conta da cobertura fraseológica de língua francesa existente nos contos, a 
produção de um manual de leitura, à guisa de um dicionário de UFs contempladas em suas diversa tipologias, com o intuito de auxiliar aos leitores brasileiros de FLE na interpretação, entendimento e tradução das UFs presentes na coleção de contos infanto-juvenis Le Petit Nicolas (GOSCINNY; SEMPÉ, 1960-1964), faz-se urgente e necessária, sendo esse um objetivo a ser realizado em pesquisas futuras.

\section{Referências}

AVOLIO, Jelssa Ciardi; FAURY, Mara Lúcia. Minidicionário francês: francêsportuguês/português-francês. São Paulo: Michaelis, 2010.

CAPELLE, Guy; MENAND, Robert. Le nouveau taxi ! 2. Méthode de français. Paris: Hachette Livre, 2009.

CHATENET, Aymar du. Le Petit Nicolas Site officiel. 2020. Disponível em: http://www.petitnicolas.com/. Acesso em: 05 set. 2020._

CUQ, Jean-Pierre; GRUCA, Isabelle. Cours de Didactique du français langue étrangère et seconde. Grenoble: Presses Universitaires, 2017.

BOLLY, Catherine. Phraséologie et collocations: approche sur corpus en français L1 et L2. Bruxelles: P.I.E Peter Lang, 2011.

DELUIGI, Paola; ROGGO, Nathalie. L'emploi de la presse dans l'enseignement de l'anglais à l'école professionnelle. 2016. $38 \mathrm{f}$. Dissertação (Master of advanced studies) - Diplôme d'enseignement pour le degré secondaire, Haute école pédagogique Vaud, Lausanne, 2016.

GALVEZ, José. Dicionário Larousse francês-português. São Paulo: Larousse do Brasil, 2006.

GONZÁLEZ-REY, María Izabel. La phraséologie du français. Toulouse: Presses Universitaires du Midi, 2015.

GOSCINNY, René; SEMPÉ, Jean-Jacques. Le Petit Nicolas. Paris: Denoël, 1960.

GoscinNY, René; SEMPÉ, Jean-Jacques. Les récrés du Petit Nicolas. Paris: Denoël, 1961.

GOSCINNY, René; SEMPÉ, Jean-Jacques. Les vacances du Petit Nicolas. Paris: Denoël, 1962.

GOSCINNY, René; SEMPÉ, Jean-Jacques. Le Petit Nicolas et les copains. Paris: Denoël, 1963.

GOSCINNY, René; SEMPÉ, Jean-Jacques. Le Petit Nicolas a des ennuis. Paris: Denoël, 1964.

MARQUES, Elizabete Aparecida; BUDNY, Rosana. Dicionários fraseológicos: o que podemos esperar desses tesouros culturais? MOARA, v. 1, p. 37-52, 2020. 
v. 11 (esp.) 366-389 ago. 2021

MATTOS, João Paulo; BRETAUD, Robert. Dicionário de idiomatismos francêsportuguês, português-francês. Rio de Janeiro: Marques Saraiva, 1990.

MEJRI, Salah. Le Figement Lexical. Cahiers de Lexicologie Revue Internationale de Lexicologie et Lexicographie, v. 82, n. 1, p. 23-39, 2003.

MEJRI, Salah. Collocations et emplois appropriés : des unités lexicales hybrides ? Cahiers de Lexicologie Revue Internationale de Lexicologie et Lexicographie, v. 98, n. 1, p. 83-94, 2011.

MEJRI, Salah. Les expressions idiomatiques. Paris: Éditions Garnier, 2017. v. 1.

MEJRI, Salah; BLANCO, Xavier. Les pragmatèmes. Paris: Classiques Garnier, 2018.

MEYSSONNIER, Stéphanie. Pourquoi et comment exploiter le support vidéo authentique en classe de langue étrangère ? $2005.56 \mathrm{f}$. Dissertação (Concours de recrutement : professeur des écoles) - IUFM de Bourgogne, Nevers, 2005.

MOGORRÓN, Pedro. La traduction des unités phraseologiques à contenu culturel. In. MOGORRÓN, Pedro; MEJRI, Salah (dirs.). Rencontres Méditerranéennes : Langues spécialisées, figement et traduction. Alicante: Quinta Impresión, 2012.

MONTEIRO-PLANTIN, Rosemeire Selma. Fraseologia - era uma vez um patinho feio no ensino de língua materna. 1. ed. Fortaleza: Imprensa Universitária, 2014.

MONTEIRO-PLANTIN, Rosemeire Selma. Fraseologia e Paremiologia: para que ensinar, se todo o mundo sabe?. ReVEL, V. 15, p. 1-16, 2017.

ORTÍZ ALVAREZ, Maria Luíza; UNTERNBÄUMEN, Enrique Huelva. Uma (re)visão da teoria e da pesquisa fraseológicas. Campinas: Pontes editores, 2011.

PAMIES, Antonio. Aux limites du limitrophe : à propos des catégories phraséologiques. In. SFAR, Inès; BUVET, Pierre-André (orgs.). La phraséologie entre fixité et congruence. Louvain-la-neuve: AcademiaL'Harmattan, 2018.

POLGUĖRE, Alain. Lexicologia e Semântica Lexical: noções fundamentais. São Paulo: Contexto, 2018.

POTTIER, Bernard. Linguistique générale : théorie et description. Paris: Klincksieck, 1974.

SAMPAIO, Angelo de Souza; RIBEIRO, Silvana Soares Costa. Unidades Fraseológicas nos Contos Le Petit Nicolas: Uma Análise Preliminar. 2018. 26 diapositivos.

SAUSSURE, Ferdinand de; BALLY, Charles; SECHEHAYE, Albert. Curso de lingüística geral. 7. ed. São Paulo, SP: Cultrix, 2006 [1916]. 
SFAR, Inès. Les énoncés formulaires : contenu pragmatique et problèmes de traduction. 2007. In: MEJRI, Salah (Org.). Â la croisée des mots : hommages à Taïeb Baccouche. Université de Sousse \& Université Paris 13, 2007, p. 313-328.

SFAR, Inès. L'analyse prédicative : un outil pour l'évaluation de la traduction des textes bilingues alignés. Synergies, Tunísia, n. 2, p. 99113, 2010.

SFAR, Inès. Les collocations dans le discours spécialisés : le cas de la terminologie ornithologique. Language Design, Espanha, n. 14. p. 19$38,2013$.

TAGNIN, Stella. o jeito que a gente diz: expressões idiomáticas e convencionais - inglês e português. São Paulo: Disal, 2013.

XATARA, Cláudia Maria. Dicionário de Expressões Idiomáticas. 2013. Disponível em: http://www.deipf.ibilce.unesp.br/pt/index.php. Acesso em 20 set. 2020.

XATARA, Cláudia Maria. Tipologia das expressões idiomáticas. ALFA: Revista de Lingüística, São Paulo, v. 42, p. 169-176, 1998 a.

ZAVAGLIA, Adriana; SILVA, Maria Cristina Parreira da; XATARA, Cláudia. Xeretando a Linguagem em Francês. Barueri - SP: DISAL, 2010.

ZUCCHI, Angela Maria Tenório. o Dicionário nos estudos de línguas estrangeiras: os efeitos de seu uso na compreensão escrita em italiano. 2010. 284 f. Tese (Doutorado em Linguística) - Faculdade Filosofia, Letras e Ciências Humanas, Universidade de São Paulo, $2010 a$.

ZUCCHI, Angela Maria Tenório. O uso de dicionários na compreensão escrita em italiano LE. In: Anne Dykstra; Tanneke Schoonheim. (Org.). Proceedings of the XIV Euralex International Congress. 1ed. Leeuwarden: Fryske Akademy, 2010b, v. 1, p. 1152-1160. 